St. Lucia, the Leewards, and Bahamas, and also in British Guiana.

In none of these areas does a tuberculosis scheme, as we know it, exist, and notification and certification are uncertain indices of the prevalence and deaths from tuberculosis.

The lack of a sufficient number of doctors resulting in considerable overwork for those there are, and the social stigma attaching to tuberculosis in the islands, does not make the detection of early treatable cases an easy matter. To add to this, the radiological facilities are of the scantiest, and hospital beds for tuberculosis cases almost nonexistent.

Dr. Santon Gilmour tells an interesting story of the history of tuberculosis in the islands. Apparently there was little tuberculosis among negro slaves, but following emancipation, when slaves were free to live where and as they liked, the disease spread, and at times reached epidemic proportions. Death rates as high ás 700 per 100,000 are said to have occurred, although by the end of last century they had fallen to approximately one-third of this figure. Recently recorded death rates from the disease have fallen continuously during the present century. In Trinidad, for instance, they have been reduced from 275 in $1896-1900$, to 100 in 1943 .

Tuberculin surveys have been carried out on the mixed negro and East Indian population of several of the islands, and the results show a high incidence of infection especially in the urban areas where more and more of the population are tending to congregate.

The housing conditions described, and the state of overcrowding existing in all the urban areas, together with the primitive sanitary arrangements, seem to be the key to the high incidence of the disease. The superstitions of the people also demand that all houses shall be hermetically sealed against the entrance of things that go bump in the night.

The prevailing type of pulmonary tuberculosis is considered from clinical observations and some post-mortem examinations; the disease pursuing a more rapid course in persons of African, than in those of East Indian origin.

The report describes a widespread survey of tropical islands, and on the basis of this survey makes recommendations as to the action which should be taken to combat the disease.

It is a fascinating piece of work, from which all workers in the tuberculosis field will profit.

C.P.H.

\section{OBSTETRICS AND GYNAECOLOGY}

By C. Scott Russell, M.B., F.R.C.S.(Edin.), M.R.C.O.G. Oxford Medical Publications. 1947. Pp. 222. 21 illustrations. Price I2s. 6d.

The style and substance of this book merit high praise. It is full: of original and sensible suggestions, and above all, it is clear of ambiguity. If only many larger textbooks were as readable and written with such artful economy of words!

But in discussing the plan and purpose of the 3 book a much harsher tone is required. We are told $\stackrel{\AA}{\varrho}$ that this book is suitable for practitioners who need. to revise their knowledge of obstetrics and $\vec{F}$. gynaecology, and it is this claim that must be questioned. If it is meant to be an account of $C$ recent advances, then why include much that is $\underline{\bar{C}}$ old and well-known? On the other hand, if it is $\frac{\bar{s}}{5}$ meant to be a statement of modern practice for a $\bar{\Phi}$ reader with no experience and little memory of his textbooks, then it must be condemned as in- $\infty$ adequate. For example, no help is given in the $\overrightarrow{0}$ management of those common cases of menorrhagia and irregular menstruation in the middle years, and $\vec{\omega}$ little guidance in the wilderness of endocrinology It might be claimed that this (and other) largeco omissions are permissible in a small book; but then 3 . why detail the treatment of placenta praevia, which is should surely not be left to a practitioner whose $\dot{\sim}$ experience and knowledge is so small ? For $y$ example, again, the account of radiological pel-in vimetry is excellent, but this is hardly an elementary ${ }_{+}^{\infty}$ subject.

It must be almost unique for a reviewer to beg an author to lengthen a book, yet what has been $\bar{z}$ presented to us is so good that we would gladly see the gaps filled in a subsequent edition, even if the covers have to swell.

\section{THE BACKGROUND OF THERAPEUTICS}

By J. H. Burn, M.D., F.R.S. Geoffrey Cumber-

lege, Oxford University Press. r948. Pp. vi $\stackrel{\circ}{\circledR}$ and 367 . Price 22s. 6d.

In the reviewer's opinion, the title of this excellent little book does not do justice to its contents. It really consists of a collection of chapters on subjects which, although unrelated to each other and necessarily chosen somewhat arbitrarily, nevertheless constitute a very adequate account of the more important recent advances in therapeutics.

The material dealt with includes such topical subjects as the thyroid and thiouracil, recent work on antihistamine substances and their role in the treatment of allergy, the malaria problem and the 0 use of the newer anti-malarial compounds, and accounts of the analeptics, steroid hormones, and alloxan diabetes. A brief account of the original physiological research which led up to the employ- of ment of the drugs in clinical medicine is always $N$ given, and the references are carefully chosen and $N$ plentiful. Perhaps not the least important section is the one entitled 'Statistics Explained.' '?

The author says he has written this book for those engaged in teaching clinical medicine, but $\Phi$ it can be thoroughly recommended as of value from $\stackrel{?}{?}$ the very beginning of clinical studies and post $T$ graduates interested in higher examinations will $\stackrel{\vec{D}}{\mathbb{S}}$ find it invaluable. 